\title{
A linear physical programming model for assembly line balancing problem
}

\author{
Muhammet Enes Akpınar \\ Department of Industrial Engineering, Engineering Faculty, Manisa Celal Bayar University, Manisa, Turkey. \\ Corresponding Author: enes.akpinar@cbu.edu.tr
}

Submitted :29/12/2020

Revised : :15/07/2021

Accepted : 27/07/2021

\begin{abstract}
This paper deals with the mixed-model assembly line balancing problem. This type of line is applied to more than one similar model of a product in an intermixed order. Despite their widespread use, these lines have received little attention in the literature. Metaheuristics, heuristics, and mathematical programming techniques are developed to solve these types of assembly line balancing problems. However, linear physical programming method has never been used. In this paper, a linear physical programming model is proposed for balancing a mixed-model assembly line. The performance of the proposed model is applied to a numerical example to analyze the usage of the methodology. Five objectives are considered in the model, and the outperformance of the methodology is demonstrated by comparing it to a different approach. According to the results, it has been seen that the proposed linear physical programming model is practical and useful approach for mixed-model assembly line balancing problems.
\end{abstract}

Keywords: Assembly; Assembly line; Line balancing; Linear physical programming; Mixed-model assembly.

\section{INTRODUCTION}

The mechanical production methods that evolved as the development of machine tools and other production aspects form the basis of mass production with the vast development of industry in the 18th and 19th centuries. Simple one-piece products were manufactured in vast quantities at these centuries. Thus, the initial stage of the mass production process is started with the production of one-piece items. Complex units were beginning to be produced in the second stage of the mass production process. During this time, mass production was referred to as flow production since the product was manufactured employing a flowing manufacturing method and assembly lines (Becker and Scholl, 2006).

Balancing an assembly line has crucial importance to provide effective assembly operations. A feasible balance can be accomplished for a line if the variation in idle times among all workstations as well as the needed number of workstations is minimized while satisfying all precedence relations (Razif et al., 2017).

Assembly lines can be grouped as multimodel, mixed, and single assembly lines as well as the task times stochastic and deterministic (Kriengkorakot and Pianthong, 2007). The single-model assembly line is used only to 
assemble one model of a product. The mixed-model assembly line is applied to more than one similar model of a product in an intermixed order. The multimodel line is employed a greater variety of base products.

In a mixed-model assembly line, different kinds of products are assembled. In other words, these are assembly lines, in which more than one same product or distinctive models of a product are manufactured simultaneously or in a mixed manner. The models in the assembly line may be different from one another according to color or used tool because of their natural demands for different tasks, precedence relations, and assignment tasks. Minimization of the number of assembly workstations, minimization of cycle time, and line efficiency are different popular objectives used in Assembly Line Balancing Problem (ALBP) (Rashid et al., 2011).

With the development of the assembly line concept, the problem of assembly line balancing emerged and this issue has attracted and continues to be seen by many scientists. ALBP is a well-known assembly line design problem, and it is about assigning tasks to stations to optimize a particular purpose. Because of optimizing critical purposes, ALBP also has a critical function particularly in the production lines (Caggiano et al., 2016).

The rest of the article is organized as follows. Firstly, literature review about ALBP is provided. Secondly, information about LPP is provided. Thirdly, the LPP formulation for ALBP is detailed. Later, detailed information and a numerical example of the proposed LPP-method are provided. Finally, conclusions and future research directions are presented.

\section{LITERATURE REVIEW}

The methodologies developed for the solution of ALBP can be grouped into three groups. The paper in the first group presents recent heuristic-based studies. Borba et al. (2018) developed an iterative beam search and branchbound based hybrid heuristic approach. Aufy and Kassam (2020) proposed a consecutive heuristic algorithm. The second group includes studies using metaheuristic approaches: genetic algorithm (Gurevsky et al., 2012; Alavidoost et al., 2015; Mura and Dini, 2016; Jusop and Rashid, 2016; Zhang et al., 2020), artificial bee colony algorithm (Tang et al., 2016; Zhao et al., 2016; Zhang et al., 2018), ant colony optimization (Zheng et al., 2012; Samouei and Dezfoulian, 2017; Huo et al., 2018; Huang et al., 2020), discrete cuckoo search (Li et al., 2018), hybrid genetic algorithm (Lin et al., 2009), simulated annealing (Dong et al., 2018; Li et al., 2018), memetic algorithm (Pereira et al., 2018), fish school search algorithm (De Albuquerque et al., 2016), migrating birds optimization metaheuristic (Janardhanan et al. 2019), and multiobjective evolution strategies (Yoosefelahi et al., 2012; Zacharia \& Nearchou, 2016).

The studies in the final group use mathematical programming techniques: GAMS-CPLEX algorithm (Esmaeilbeigi et al., 2015) and excel (Wei and Chao, 2011). Two recent studies by Make et al. (2017) and Eghtesadifard (2020) ensured a comprehensive review of the assembly line balancing literature with their solutions. The reader may also refer to Sivasankaran and Shahabudeen (2014) for more studies. Although many objectives are taken into account in the methods based on the ALBPs model in the literature, the most important disadvantage of these methods is that the decision-maker cannot make his/her options in a physically expressive way while considering each objective. In other words, since the decisions made by the decision-maker do not have any tangible meaning, the consistency of the criteria weights obtained as a result of the comparisons is very low.

In this study, the Linear Physical Programming (LPP) method is used, which enables the decision-maker to define his/her options in a physically expressive way for each of the objectives. Thanks to this proposed method, the process of determining exact weights, which causes consistency problems in previously proposed methods and forces decision-makers to make subjective decisions and intangible comparisons, has been eliminated. The importance of this study is primarily to fill the gap caused by the fact that the LPP method has not been used in ALBP before in the 
literature. Another aim is to analyze whether this method provides an advantage over the previous methods used in the literature.

\section{LINEAR PHYSICAL PROGRAMMING METHOD}

In multiple criteria decision-making methodologies such as analytical network process and goal programming, the main difficulty for decision-makers is to determine the weights within the benefits function. The LPP overcomes this challenge by allowing decision-makers by expressing their preferences for each criterion using 4 class functions. Criterion weights are determined by an algorithm specific to LPP according to the preference values for each criterion decided by the decision-maker. Thus, the decision-maker is not directly involved in the weight determination process (Messac et al., 1996). In LPP, the decision-maker can use one of the 4 class functions presented in Figure 1. This figure contains the values $\left(t_{p}\right)$ for the criteria evaluated on the horizontal axis. As for the vertical axis, it contains the class function $\left(z_{p}\right)$, which is desired to be minimized for each of the criteria. The class function is asked to take small values, and its ideal value is zero. Preference intervals on the horizontal axis while evaluating any alternative $p$. It is used to categorize the values related to the criteria. These intervals can be expressed as follows for the 1S class:

- $g_{p} \geq t_{p 5}^{+}$(Unacceptable interval)

- $t_{p 4}^{+} \leq g_{p} \leq t_{p 5}^{+}$(Highly undesirable interval)

- $t_{p 3}^{+} \leq g_{p} \leq t_{p 4}^{+}$(Undesirable interval)

- $t_{p 2}^{+} \leq g_{p} \leq t_{p 3}^{+}$(Tolerable interval)

- $t_{p 1}^{+} \leq g_{p} \leq t_{p 2}^{+}$(Desirable interval)

- $g_{p} \leq t_{p 1}^{+}$(Ideal interval).

The preferences for the $p$ th criterion are expressed by specifying the physical values of the quantities $t_{p 1}^{+}$ through $t_{p 5}^{+}$. Assume that a decision-maker collects the following values in order to determine the cost parameter from $t_{p 1}^{+}$to $t_{p 5}^{+}$in pounds: $(7000,5000,3500,2500,1500)$. With these values, the cost of the $£ 1000$ alternative will be included in the ideal interval, while the cost of the $£ 4000$ alternative will be included in the undesirable interval, and so on until the determination of interval procedure is completed. The LPP steps are as follows:

1. For each criterion used in evaluating alternatives, the decision-maker selects one of the class functions provided in Figure 1.

2. For each criterion, the decision-maker establishes distinct intervals (target values) of attraction degrees. As seen in the horizontal axes of the functions given in Figure 1, there are five intervals in class 1S, five intervals in class $2 \mathrm{~S}$, nine intervals in class $3 \mathrm{~S}$, and ten intervals in class $4 \mathrm{~S}$.

3. The LPP weight algorithm is used to calculate the weights as given below:

a. begin: $\quad \alpha=2.2 ; r_{p 1}^{+}=0, r_{p 1}^{-}=0, \tilde{s}^{2}=$ small affirmative value (say, 0.02 )

$p=0 ; m=1, m_{\mathrm{c}}=$ is criteria number

b. $\operatorname{set} p=p+1$,

c. set $m=m+1$ evaluate the sequence:

$\tilde{s}^{m}, \tilde{t}_{p m}^{+}, \tilde{t}_{p m}^{-}, \tilde{r}_{p m}^{+}, \tilde{r}_{p m}^{-}, r_{p m}^{+}, r_{p m}^{-}, \tilde{r}_{\text {min }}$ if the pre-determined small positive number (say, 0.002) is greater than

$\tilde{r}_{\text {min }}$, increase $\alpha$ then go to ii.

d. if $m \neq 5$, go to step c.

e. if $p \neq m_{\mathrm{c}}$, go to step $\mathrm{b}$. 
where $m$ is the interval factor, $m_{\mathrm{c}}$ is the numbers of criteria, $p$ is the criteria factor, $r_{p m}^{-}$and $r_{p m}^{+}$are negative and positive weights for the $p$ criteria in interval $m, \tilde{r}_{\text {min }}$ is the minimal value of $\tilde{r}_{p m}^{+}$and $\tilde{r}_{p m}^{-}$, and $s p$ is the function included in the interval for $p$ criteria; $\tilde{s}^{m}$ is the changes in $s p$ value against interval $m$ value, $\tilde{t}_{p m}^{-}$and $\tilde{t}_{p m}^{+}$are the negative and positive sides of the $p$ th criterion in the size of $s$ th intervals, and $\tilde{r}_{p m}^{-}$and $\tilde{r}_{p m}^{+}$are negative and positive normalized weights for the $p$ th criterion in interval and convexity factor represented with $\alpha$ (Messac et al., 1996).

\section{Calculate the total score for each alternative.}
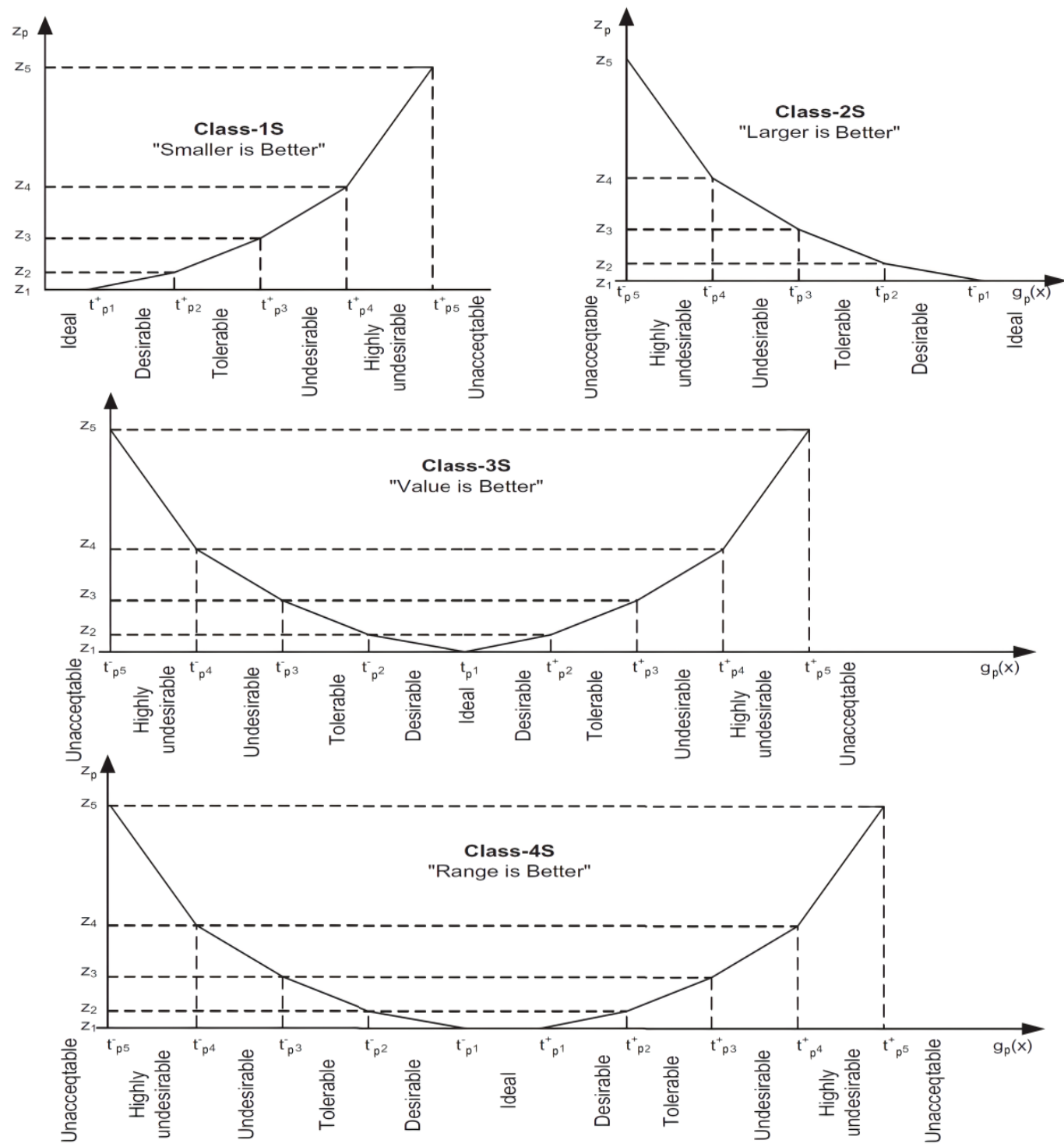

Figure 1. Class functions in LPP. 


\section{PROBLEM DESCRIPTION AND FORMULATION}

In this section, the applicability of the proposed LPP-based method in a home appliances industry is discussed. One of the most difficult stages in a decision-making process for the decision-maker is defining a weight process. This process is not an effective way to gather the exact preferences because of subjectivity. In LPP, assignment of exact physically meaningless weights to goals does not require, instead of this, LPP permit to decision-maker defining their choices by considering physically expressive preference intervals for each objective. Thus, the data collection process is being much more facilitated. Furthermore, the uncertainness of each objective is intentionally regarded by allowing the decision-maker to define her/his options as intervals in place of exact scores.

A LPP methodology for mixed-model assembly line balancing problem is improved in this study by considering Samouei and Ashayeri (2019), Choi (2009), Fathi et al. (2018), Gokcen and Erel (1997) mathematical models. The decision variables are as follows:

$D \quad$ the total number of tasks

$S \quad$ the total number of workstations

$P \quad$ the total number of product kinds

$t_{i n} \quad$ Process time for $i$ th task of $n$th model $i=1, \ldots, D ; n=1, \ldots, P$

$C_{n} \quad n$th model cycle time, $n=1, \ldots, P$

$A_{i s} \quad 1$ if $i$ th task is assigned to $s$ th workstation, 0 otherwise, $s=1, \ldots, S ; i=1, \ldots, D$

$Y_{s n} \quad 1$ if $n$th model is assigned to $s$ th workstation, 0 otherwise, $n=1, \ldots, P ; s=1, \ldots, S$

$X_{s} \quad 1$ if $s$ th workstation is used for all models, 0 otherwise, $s=1, \ldots, S$

$U_{\text {in }} \quad 1$ if $i$ th task is needed for $n$th model, 0 otherwise, $n=1, \ldots, P ; i=1, \ldots, D$

The LPP-based methodology assumptions are as follows:

On a one-sided straight assembly line, different models of the same basic product with identical production features are built. The assembly line is a fast-moving line that produces a mixed-model product. Priority restrictions link the assembly tasks together. A task that requires assembly cannot be distributed among numerous workstations. At any given time, only one task can be completed at a workstation. The amount of time it takes to complete a task is independent of the workstation to which it is assigned. Work-in process, set-up times, and parallel workstations are negligible. Any workstation can be used to complete a task. Each assembly task's processing time is known and deterministic.

\section{MATHEMATICAL MODEL}

The mathematical formulations of the proposed ALBP model are improved by considering five objectives. Objective first (equation-1) is to minimize cycle time for all models. The second objective (2) minimizes the number of used workstations. The third objective (3) minimizes the different models' slack time differences, while the fourth objective (4) minimizes the total idle time. The final objective (5) aim is to maximize the line efficiency of the line. 
$O_{1}=\min \sum_{n=1}^{P} C_{n}$

$O_{2}=\min \sum_{s=1}^{S} A_{i s}=1 \quad \forall i=1,2, \ldots, D$

$O_{3}=\min \sum_{n=1}^{P} \alpha$

$O_{4}=\min \sum_{s=1}^{S} \sum_{n=1}^{P} h_{s n}^{-}$

$O_{5}=\max \sum_{S=1}^{S} \sum_{i=1}^{D} t_{i n} \cdot A_{i s} /\left(C_{n} . S\right) \quad n=1, \ldots . P$

$\sum_{i=1}^{D} U_{i n} . A_{i s}-U_{i n} . Y_{s m} \leq 0, \quad s=1, \ldots, S, \quad n=1, \ldots . P$

$\sum_{n=1}^{P} Y_{s n}-P \cdot X_{s}=0 \quad s=1, \ldots, S$

$Y_{s m}-\sum_{i=1}^{D} U_{i n} \cdot A_{i s} \leq 0, \quad s=1, \ldots, S, \quad n=1, \ldots . P$

$\sum_{s=1}^{S} X_{s} \leq W S, \quad s=1, \ldots, S$

$\sum_{s=1}^{S} X_{S}+d^{w s-}-d^{w s+}=W S, \quad s=1, \ldots, S$

$\sum_{i=1}^{D} t_{i n} \cdot A_{i s} \leq C_{n}, \quad s=1, \ldots, S, \quad n=1, \ldots . P$

$\sum_{i=1}^{D} t_{i n} \cdot A_{i s}+h_{s n}^{-}+P_{s n}=C_{n}, \quad s=1, \ldots, S, \quad n=1, \ldots . P$

$P_{s n} \leq\left(1-Y_{s n}\right) * N, \quad s=1, \ldots, S, \quad n=1, \ldots . P$

$\left|h_{s n}^{-}-h_{s n+1}^{-}-\left(1-Y_{s n}\right) * C_{n}\right| \leq \alpha, \quad s=1, \ldots, S, \quad n=1, \ldots . P-1$ 


$$
\begin{aligned}
& \sum_{s=1}^{S} S . A_{i s}-\sum_{s=1}^{S} S . A_{j s} \leq 0, \quad \forall i \leq j, i=1, \ldots, D \quad j=1, \ldots, D \\
& \sum_{S=1}^{S} A_{i s}=1, \quad \forall i=1, \ldots, D \\
& X_{S}, A_{i s}, Y_{s n}, U_{i n}: 0-1 \text { integer value }
\end{aligned}
$$

Constraints (6)-(8) guarantee that if an unassigned task is assigned to a new workstation, a new workstation must be allocated. A new workstation will be allocated for whole assembly line models only when the workstation is allocated just for at least one assembly line model. Allocated workstations for each assembly line model will be included a task from different assembly line models. Constraint (9) handles to restrict the opened number of workstations. Constraint (10) ensures the necessary deviation factors. Constraint (11) is for the calculation of cycle time and with the task, assignment operations are ended for all assembly models the total time of tasks assigned to a workstation must less or equal to cycle time. Constraints (12) and (13) guarantee that $h_{s n}^{-}$will not take a value, and $P_{s n}$ factor takes value only when the workstation $s$ is not used for model $n$. Constraint (14) evaluates that a predefined $\alpha$ value can limit the difference of $h_{s n}^{-}$deviation factors. By using this limitation idle time differences among the workstations will not be greater than $\alpha$. Constraint (15) preserves the precedence relations during the assignment of tasks to the workstations. Constraint (16) ensures that each assembly model's task assignment is limited to one workstation.

\section{APPLICATION OF THE LPP METHOD}

This study considers the design of an assembly line for the assembly of machines. Two different product types are considered: washing machine and tumble dryer (dryer machine). Precedence relations and processing times of products are illustrated in Table 1. Precedence relations graphs for washing machine and tumble dryer are presented in Figures 2 and 3, respectively. Figure 4 represents an integrated precedence graph.

All five goals described in the LPP formulation section were modeled by considering Class 2S LPP functions. Table 2 presents the payoff table for upper and lower values of one objective, and the limitation of Class 2 LPP functions was decided by regarding these values. LPP limitation values are given in Table 3. LPP weight algorithm is used to decide LPP weights. The proposed LPP based assembly line balancing methodology weights are provided in

Table 4.

Abd El-Wahed and Lee (2006) comparison procedure is used to compare the performance of the proposed LPP to Fuzzy Goal Programming (FGP) performance. The numerical example model was solved by using Lingo 12.0. Table 5 presents the workstations times and task assignments of each model. Table 6 presents the outcomes of LPP and concerning results; the first objective $\left(\mathrm{O}_{1}\right)$ function values are $35 \mathrm{~s}$ and $45 \mathrm{~s}$ for model 1 and model 2 , respectively. The difference is $10 \mathrm{~s}$, and this value is considered for comparison. The second objective $\left(\mathrm{O}_{2}\right)$ function minimizes the summation of workstations, and the deviation from the predetermined workstation number (4) is 1 workstation since the summation of workstations to be allocated was stated as 5 . The third objective $\left(\mathrm{O}_{3}\right)$ function value is $7 \mathrm{~s}$, and this objective minimizes the slack time differences between assembly models in a workstation. To minimize the solution of the fourth objective $\left(\mathrm{O}_{4}\right)$ function, there is a $29 \mathrm{~s}$ total idle time. The fifth and the final objective $\left(\mathrm{O}_{5}\right)$ function takes the value of 0.923 as maximized line efficiency value. 


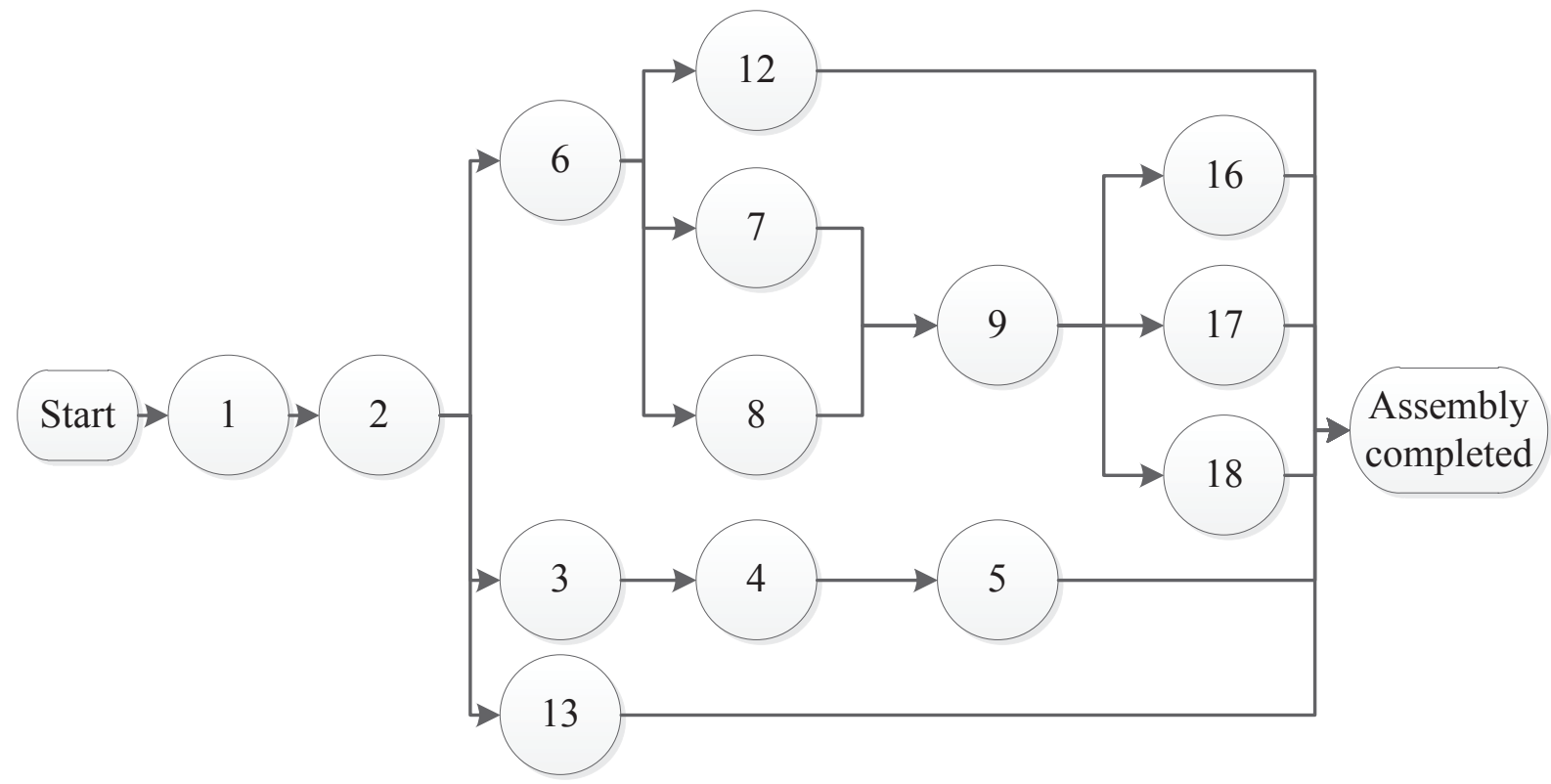

Figure 2. Precedence relation graph for washing machine.

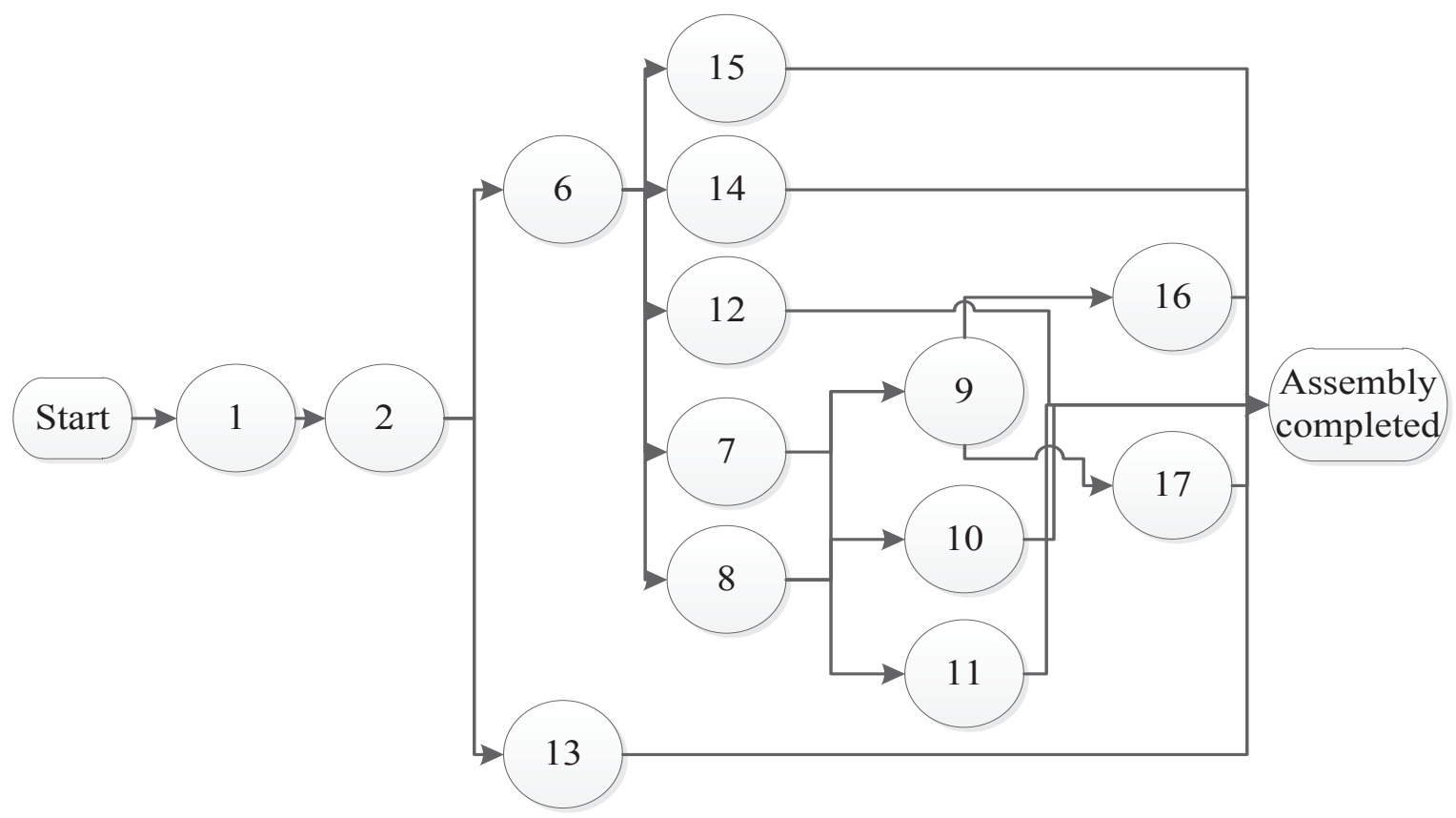

Figure 3. Precedence relation graph for tumble dryer. 
Table 1. Precedences and processing times for washing machine and tumble dryer.

\begin{tabular}{|c|c|c|c|c|}
\hline $\begin{array}{c}\text { Task } \\
\text { Number }\end{array}$ & $\begin{array}{l}\text { Part } \\
\text { Name }\end{array}$ & $\begin{array}{l}\text { Process time } \\
(\mathrm{WM})(\mathrm{s})\end{array}$ & $\begin{array}{l}\text { Process time } \\
\text { (TD) (s) }\end{array}$ & $\begin{array}{l}\text { Precedence } \\
\text { relationships }\end{array}$ \\
\hline 1 & Drum support rollers & 8 & 12 & - \\
\hline 2 & Drum & 20 & 30 & 1 \\
\hline 3 & Drain pump & 15 & - & 2 \\
\hline 4 & Filter & 10 & - & 3 \\
\hline 5 & Drain hose & 5 & - & 4 \\
\hline 6 & Motor & 35 & 30 & 2 \\
\hline 7 & Drive Belt & 20 & 25 & 6 \\
\hline 8 & Heater & 15 & 15 & 6 \\
\hline 9 & Outer cover & 45 & 40 & 7,8 \\
\hline 10 & Thermostats & - & 10 & 8 \\
\hline 11 & Vent & - & 15 & 8 \\
\hline 12 & Power supply & 3 & 3 & 6 \\
\hline 13 & Water supply hoses & 6 & - & 2 \\
\hline 14 & Blower & - & 20 & 6 \\
\hline 15 & Exhaust duct & - & 10 & 6 \\
\hline 16 & Door & 15 & 20 & 9 \\
\hline 17 & Control panel & 10 & 15 & 9 \\
\hline 18 & Detergent drawer & 10 & - & 9 \\
\hline
\end{tabular}

Table 2. Payoff values.

\begin{tabular}{|c|c|c|c|c|c|}
\hline & $\mathrm{Z}_{1}$ & $\mathrm{Z}_{2}$ & $\mathrm{Z}_{3}$ & $\mathrm{Z}_{4}$ & $\mathrm{Z}_{5}$ \\
\hline $\mathrm{O}_{1}$ & 0 & 5 & 18 & 113 & 0.908 \\
\hline $\mathrm{O}_{2}$ & 46 & 0 & 7 & 49 & 0.863 \\
\hline $\mathrm{O}_{3}$ & 66 & 2 & 1 & 186 & 0.856 \\
\hline $\mathrm{O}_{4}$ & 18 & 3 & 5 & 33 & 0.924 \\
\hline $\mathrm{O}_{5}$ & 0.923 & 0.838 & 0.889 & 0.917 & 0.819 \\
\hline
\end{tabular}

Table 3. LPP limit values.

\begin{tabular}{|c|c|c|c|c|c|}
\hline & $t_{p 5}^{-}$ & $t_{p 4}^{-}$ & $t_{p 3}^{-}$ & $t_{p 2}^{-}$ & $t_{p 1}^{-}$ \\
\hline $\mathrm{O}_{1}$ & 56.5 & 45 & 20 & 15 & 0 \\
\hline $\mathrm{O}_{2}$ & 8 & 6 & 3 & 2 & 0 \\
\hline $\mathrm{O}_{3}$ & 20 & 15 & 5 & 3 & 0 \\
\hline $\mathrm{O}_{4}$ & 186 & 65 & 42 & 34 & 25 \\
\hline $\mathrm{O}_{5}$ & 0.969 & 0.919 & 0.881 & 0.851 & 0.818 \\
\hline
\end{tabular}


Table 4. LPP weights.

\begin{tabular}{|c|c|c|c|c|}
\hline & $r_{p 5}^{-}$ & $r_{p 4}^{-}$ & $r_{p 3}^{-}$ & $r_{p 2}^{-}$ \\
\hline $\mathrm{O}_{1}$ & 33.561 & 0.823 & 0.352 & 0.052 \\
\hline $\mathrm{O}_{2}$ & 138.600 & 11.300 & 1.100 & 0.102 \\
\hline $\mathrm{O}_{3}$ & 6.866 & 3.560 & 0.250 & 0.051 \\
\hline $\mathrm{O}_{4}$ & 9.356 & 0.510 & 0.110 & 0.014 \\
\hline $\mathrm{O}_{5}$ & 60.450 & 9.690 & 0.420 & 0.112 \\
\hline
\end{tabular}

Table 6 represents the best value of ideal solution for a definite objective function considering Table 2 payoff values. As shown in Table 6, for A values, the LPP method puts forward quite promising performance compared to FGP (Abd El-Wahed and Lee, 2006). All these outcomes represent that, to solve ALBP, the LPP method is an encouraging solution approach.

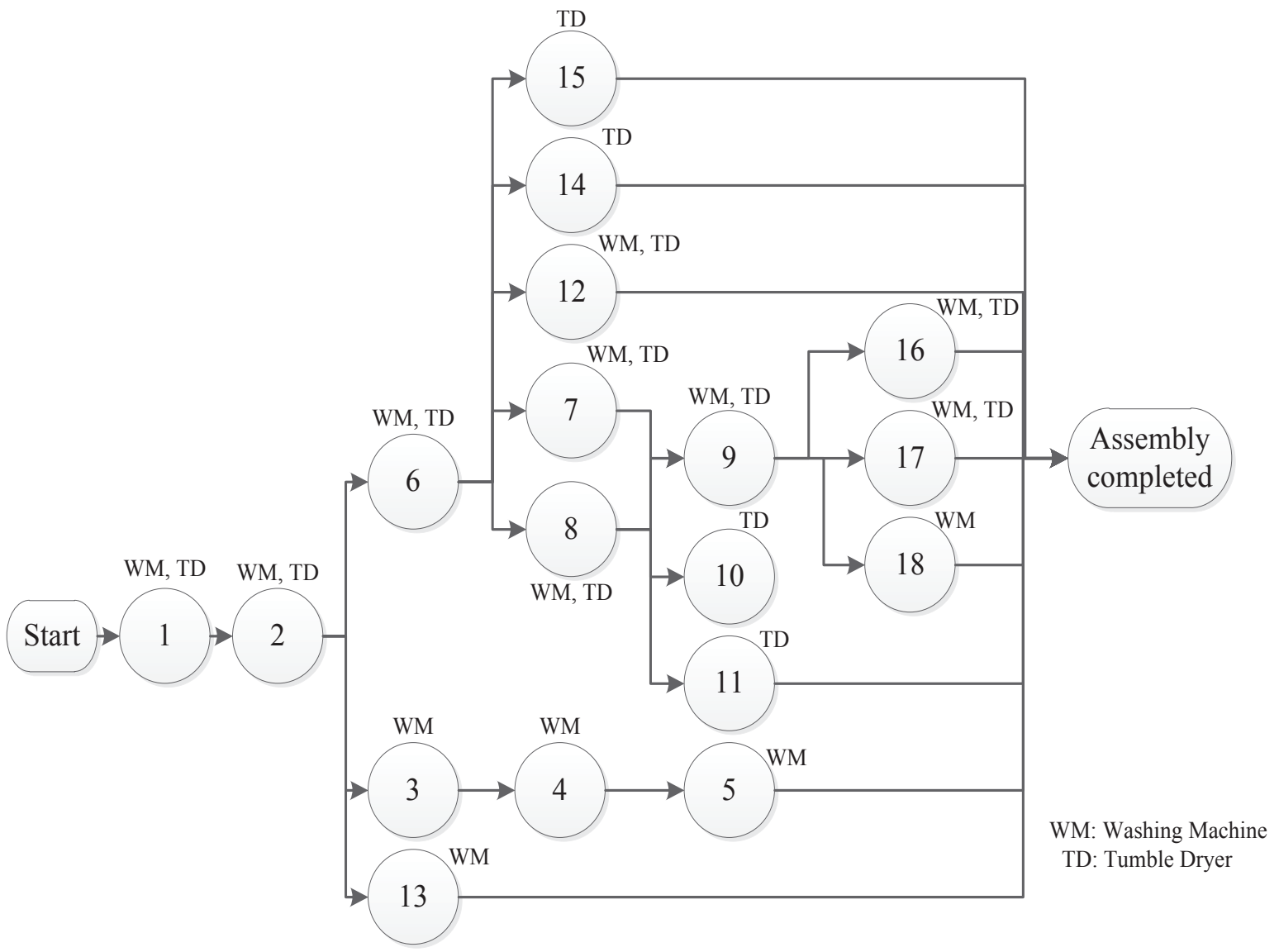

Figure 4. Integrated precedence relation graph. 
Table 5. Assigned tasks to allocated workstations.

\begin{tabular}{|c|c|c|c|c|c|}
\hline & & \multicolumn{2}{|c|}{ Model 1 (Washing Machine) } & \multicolumn{2}{c|}{ Model 2 (Tumble Dryer) } \\
\hline Stations & Tasks & Tasks & Station Time & Tasks & Station Time \\
\hline 1 & $1,2,3,4,7$ & $1,2,3$ & 43 & 1,2 & 42 \\
\hline 2 & $5,6,8,10$ & $4,5,6$ & 50 & 6,7 & 55 \\
\hline 3 & $9,12,14$ & 7,8 & 35 & 8,9 & 55 \\
\hline 4 & $11,13,16$ & 9,12 & 48 & $10,11,12,14$ & 48 \\
\hline 5 & $15,17,18$ & $13,16,17,18$ & 41 & $15,16,17$ & 45 \\
\hline
\end{tabular}

Table 6. LPP-based methodology and FGP results comparison.

\begin{tabular}{|l|l|l|}
\hline & Linear Physical Programming & Fuzzy Goal Programming \\
\hline $\mathrm{O}_{1}$ & 10 & 15.568 \\
\hline $\mathrm{O}_{2}$ & 1 & 3 \\
\hline $\mathrm{O}_{3}$ & 7 & 5.458 \\
\hline $\mathrm{O}_{4}$ & 29 & 32.454 \\
\hline $\mathrm{O}_{5}$ & 0.923 & 0.912 \\
\hline $\mathrm{A}_{1}$ & 0.915613547 & 0.915658650 \\
\hline $\mathrm{A}_{2}$ & 0.536914523 & 0.556845390 \\
\hline $\mathrm{A}_{3}$ & 0.514858586 & 0.524958400 \\
\hline $\mathrm{A}_{4}$ & 0.335894752 & 0.345589420 \\
\hline $\mathrm{A}_{\infty}$ & 0.241070500 & 0.246080600 \\
\hline
\end{tabular}

\section{CONCLUSION}

Mixed-model assembly line balancing research is crucial to consider for adaptability and productivity because it has a direct impact on the production system's efficiency. Mixed-model assembly lines are preferred over singlemodel assembly lines in the current market, which is characterized by a growing pattern for a bigger product or item variation. To meet open market demand, more and more businesses, such as the home appliances industry, are transitioning from traditional and manual methods to semi- and fully automated systems. In this study, an assembly line balancing approach based on LPP was developed for white good products. The LPP-based method was implemented to balance a machine assembly line including mixed-model assembly lines. Five different objective functions are considered, and the value for $\left(\mathrm{O}_{1}\right)$ is $10,\left(\mathrm{O}_{2}\right) 1,\left(\mathrm{O}_{3}\right) 7 \mathrm{~s},\left(\mathrm{O}_{4}\right)$ 0.29s, and $\left(\mathrm{O}_{5}\right)$ 0.923. These results show that the LPP-based assembly line balancing approach provides quite promising result. 
The proposed approach can provide the following managerial insights:

- Deterministic or stochastic process times could be seen in the assembly operations. While balancing mixed-model assembly lines, the proposed approach allows decision makers to consider deterministic issues.

- The LPP technique gives decision-makers the option of employing interval ranges.

The limitations of the study are as follows:

- In real-life problems, processing times can be stochastic. However, stochastic processing times were not taken into account in this study.

- The number of components considered in the proposed method is reasonable. More complex models or components can take a long time to solve.

The proposed LPP-based method should be enhanced by considering stochastic process times by using simulation optimization methodology. Although the proposed approach is applied to mixed-model ALBP, it could also be tested by applying to different ALBPs for further research.

\section{REFERENCES}

Abd El-Wahed, W. F. \& Lee, S. M. 2006. Interactive Fuzzy Goal Programming for Multi-objective Transportation Problems. Omega, 34(2): 158-166.

Alavidoost, M. H., Tarimoradi, M. \& Zarandi, M. F. 2015. Fuzzy adaptive genetic algorithm for multiobjective assembly line balancing problems. Applied soft computing, 34(1): 655-677.

Aufy, S. A., \& Kassam, A. H. 2020. A consecutive heuristic algorithm for balancing a mixed-model assembly line type II using a (W-TAWH) model developed for straight and U-shaped layouts. In IOP Conference Series: Materials Science and Engineering, 671:1 12147.

Becker, C. \& Scholl, A. 2006. A survey on problems and methods in generalized assembly line balancing. European Journal of Operation Research, 168(3): 694-715.

Borba, L., Ritt, M. \& Miralles, C. 2018. Exact and heuristic methods for solving the robotic assembly line balancing problem. European Journal of Operational Research, 270(1): 146-156.

Caggiano, A., Marzano, A. \& Teti, R. 2016. Resource efficient configuration of an aircraft assembly line. Procedia CIRP, 41(1): 236-241.

Choi, G. 2009. A goal programming mixed-model line balancing for processing time and physical workload. Computers \& Industrial Engineering, 57(1): 395-400.

De Albuquerque, I. M., Monteiro F. J., de Lima N. F. B. \& de Oliveira S. A. M. 2016. Solving assembly line balancing problems with fish school search algorithm. In 2016 IEEE Symposium Series on Computational Intelligence, 1-8.

Dong, J., Zhang, L., \& Xiao, T. 2018. A hybrid PSO/SA algorithm for bi-criteria stochastic line balancing with flexible task times and zoning constraints. Journal of Intelligent Manufacturing, 29(4): 737-751.

Eghtesadifard, M., Khalifeh, M. \& Khorram, M. 2020. A systematic review of research themes and hot topics in assembly line balancing through the web of science within 1990-2017. Computers \& Industrial Engineering, 139(1): 106182.

Esmaeilbeigi, R., Naderi, B. \& Charkhgard, P. 2015. The type E simple assembly line balancing problem: A mixed integer linear programming formulation. Computers \& Operations Research, 64: 168-177. 
Fathi, M., Fontes, D. B. M. M., Moris, M. U., \& Ghobakhloo, M. 2018. Assembly line balancing problem: A comparative evaluation of heuristics and a computational assessment of objectives. Journal of Modelling in Management, 37(2): 201-527.

Gurevsky, E., Battaïa, O., \& Dolgui, A. 2012. Balancing of simple assembly lines under variations of task processing times. Annals of operations research, 201(1): 265-286.

Gokcen, H., \& Erel, E. 1997. A goal programming approach to mixed-model assembly line balancing problem. International Journal of Production Economics, 48(2): 177-185.

Huo, J., Wang, Z., Chan, F. T., Lee, C. K., \& Strandhagen, J. O. 2018. Assembly line balancing based on beam ant colony optimisation. Mathematical Problems in Engineering, 2018: 1-17.

Huang, F., Wang, H., Gu, J., \& Sun, Q. 2020. Ant colony optimization approach based on precedence constraint matrix for flexible process planning. Journal of Engineering Research, 8(1): 272-293.

Janardhanan, M. N., Li, Z., Bocewicz, G., Banaszak, Z. \& Nielsen, P. 2019. Metaheuristic algorithms for balancing robotic assembly lines with sequence-dependent robot setup times. Applied Mathematical Modelling, 65: 256-270.

Jusop, M., \& Ab Rashid, M. F. F. 2016. Optimisation of assembly line balancing type-E with resource constraints using NSGA-II. In Key Engineering Materials, 701: 195-199.

Kriengkorakot, N. \& Pianthong, N. 2007. The assembly line balancing problem: review articles. Engineering and Applied Science Research, 34(2): 133-140.

Lin, Y. Y., Che, Z. G. H., Chiang, T., Che, Z. G. H. \& Chiang, C. J. 2009. A bi-objective model for concurrent planning of supplier selection and assembly sequence planning. Global Perspective for Competitive Enterprise, Economy and Ecology, 573-580.

Li, Z., Janardhanan, M. N., Nielsen, P. \& Tang, Q. 2018. Mathematical models and simulated annealing algorithms for the robotic assembly line balancing problem. Assembly Automation, 38(4): 420-436.

Li, Z., Dey, N., Ashour, A. S. \& Tang, Q. 2018. Discrete cuckoo search algorithms for two-sided robotic assembly line balancing problem. Neural Computing and Applications, 30(9): 2685-2696.

Make, M. R. A., Rashid, M. F. F. A. \& Razali, M. M. 2017. A review of two-sided assembly line balancing problem. The International Journal of Advanced Manufacturing Technology, 89(5): 1743-1763.

Messac, A., Gupta, S. \& Akbulut, B. 1996. Linear Physical Programming: A New approach to Multiple Objective Optimization. Transactions on Operational Research, 8(2): 39-59.

Mura, M. D., \& Dini, G. 2016. Worker skills and equipment optimization in assembly line balancing by a genetic approach. Procedia CIRP, 44: 102-107

Pereira, J., Ritt, M. \& Vásquez, Ó. C. 2018. A memetic algorithm for the cost-oriented robotic assembly line balancing problem. Computers \& Operations Research, 99: 249-261.

Rashid, M., Hutabarat, W. \& Tiwari, A. 2011. A review on assembly sequence planning and assembly line balancing optimization using soft computing approaches The International Journal of Advanced Manufacturing Technology, 59(1): 335-349

Razif, M., Make, A., Fadzil, M., Ab, F., Make, M. R. A., Rashid, M. F. F. A. \& Razali, M. M. 2017. A review of two-sided assembly line balancing problem. The International Journal of Advanced Manufacturing Technology, 89(5): 1743-1763.

Samouei, P., \& Dezfoulian, H. R. 2017. A note on 2-ANTBAL: An ant colony optimisation algorithm for balancing two-sided assembly lines. Computers \& Industrial Engineering, 110: 229-230. 
Samouei, P., \& Ashayeri, J. 2019. Developing optimization \& robust models for a mixed-model assembly line balancing problem with semi-automated operations. Applied Mathematical Modelling, 72: 259-275.

Sivasankaran, P, \& Shahabudeen, P. 2014. Literature review of assembly line balancing problems. The International Journal of Advanced Manufacturing Technology, 73(9): 1665-1694

Tang, Q., Li, Z., \& Zhang, L. 2016. An effective discrete artificial bee colony algorithm with idle time reduction techniques for two-sided assembly line balancing problem of type-II. Computers \& Industrial Engineering, 97: 146-156.

Wei, N. C. \& Chao, I. M. 2011. A solution procedure for type E simple assembly line balancing problem. Computers \& Industrial Engineering, 61(3): 824-830.

Yoosefelahi, A., Aminnayeri, M., Mosadegh, H. \& Ardakani, H. D. 2012. Type II robotic assembly line balancing problem: An evolution strategies algorithm for a multi-objective model. Journal of Manufacturing Systems, 31(2): 139-151.

Zacharia, P. T., \& Nearchou, A. C. 2016. A population-based algorithm for the bi-objective assembly line worker assignment and balancing problem. Engineering Applications of Artificial Intelligence, 49: 1-9.

Zheng, Q. X., Li, Y. X., Li, M. \& Tang, Q. H. 2012. An improved ant colony optimization for large-scale simple assembly line balancing problem of type-1. Applied Mechanics and Materials, 159: 51-55.

Zhang, J., Zhang, X., Tang, H., Zhang, Q., Hua, X., Ma, X. \& Wai, C. M. 2018. Allele-defined genome of the autopolyploid sugarcane Saccharum spontaneum L. Nature genetics, 50(11): 1565-1573.

Zhang, B., Xu, L., \& Zhang, J. 2020. A multi-objective cellular genetic algorithm for energy-oriented balancing and sequencing problem of mixed-model assembly line. Journal of Cleaner Production, 244: 118845.

Zhao, X., Hsu, C. Y., Chang, P. C., \& Li, L. 2016. A genetic algorithm for the multi-objective optimization of mixed-model assembly line based on the mental workload. Engineering Applications of Artificial Intelligence, 47: 140-146. 